\title{
Short-Term Wind Power Forecasting Using Artificial Neural Networks for Resource Scheduling in Microgrids
}

\author{
Abinet Tesfaye \\ School of Electrical and \\ Electronic Engineering, North \\ China Electric Power \\ University, and \\ Goldwind and Etechwin \\ Electric Co., Ltd \\ Beijing, China \\ D. H. Zheng \\ Goldwind and Etechwin \\ Electric Co., Ltd \\ Beijing, China
}

\author{
J. H. Zhang \\ School of Electrical and \\ Electronic Engineering, North \\ China Electric Power \\ University \\ Beijing, China
}

\author{
Dereje Shiferaw \\ Department of Electrical and \\ Computer Engineering, Adama \\ Science and Technology \\ University \\ Adama, Ethiopia
}

\begin{abstract}
Use of wind power as one of renewable resources of energy has been growing quickly all over the world. Wind power generation is significantly vacillating due to the wind speed alteration. Therefore, assessment of the output power of this type of generators is always associated with some uncertainties. A precise wind power prediction aims to support the operation of large power systems or microgrids in the scope of the intraday resources scheduling model, namely with a time horizon of 5-10 minutes, and this can efficiently uphold transmission and distribution system operators to improve the power network control and management. A Shortterm ANN based wind power prediction model, for day-ahead energy management and scheduling in microgrids, is developed utilizing a real database of 12 months with 10 minutes time interval data from measured information of online supervisory control and data acquisition (SCADA) of Goldwind microgrid wind turbine system (Beijing, China) as well as Numerical Weather Prediction (NWP). The ANN predicted wind power has been compared with the actual power of Goldwind wind turbine system. The predicted wind power has shown acceptable agreement with the actual power output that has been recorded by the SCADA which confirms the robustness and accuracy of the ANN wind power forecasting model developed in this research paper.
\end{abstract}

Keywords: Artificial neural network, microgrid, numerical weather predictions, resource scheduling, supervisory control and data acquisition, wind power prediction.

\section{INTRODUCTION}

Kyoto Protocol with the aim of achieving the "stabilization of greenhouse gas concentrations in the atmosphere at a level that would prevent dangerous anthropogenic interference with the climate system" is an environmental convention [43]. By adopting this protocol, due to environmental benefits of renewable resources particularly wind power generation, utilization of these types of energy has acquired noticeable consideration in eye-catching number of countries, recently. In comparison with the environmental damages of traditional sources of energy, the ecological influences of wind power is relatively negligible [43].

In fact, wind power fuel usage is incomparable with fossil power plants as well as fuel emission. Furthermore, wind power enjoys infinitesimal progress expenses, in addition to an average cost of investigation. However, despite remarkable environmental benefits, the continuous and chaotic fluctuations of wind speed make the output power of wind farms completely stochastic and different from those of conventional units. However, instant electrical generation must be equal to the grid consumption to fulfill the network stability requirements and the spare capacity may be reduced in the power system [43].

Due to this uncertainty, it may bestow ample challenges to connect large quantities of wind power into a power system. However, this challenge is not insuperable. In order to increase the economic efficiency and acceptability of the wind power and to permit a diminishing in the punishment of an instantaneous spot market coming from extra estimation or underrating of the production, the exact prediction of wind power as well as wind velocity is required. Surely, a reliable prediction system can help distribution system operators and 
power marketers to make a better decision on critical situation [43].

Nowadays, several methods have been developed to predict the wind power and speed. Existing methods can be arranged as statistical, physical and time series modeling methods based on the used prediction models [1]. The physical methods are based on local meteorological service or NWP model data of the lower atmosphere (i.e. in relation with atmospheric pressure degree, at $2 \mathrm{~m}$ or $10 \mathrm{~m}$ heights above the ground) associated with topological data like obstacles, roughness and orography. The core idea of physical approaches is to estimate generation power of the wind turbine with outsourcing these obtained data up or down to exact height of the wind turbine hub and then, utilizing the manufacturer's power curve for the logarithmic power law or the specific wind turbine. Statistical forecasting techniques are only based on one or more models. These approaches found coordination between predict and historical numerical quantity of meteorological parameters and wind power measurements associated with the power quantities coming from historical data [43].

Moreover, statistical models enjoy freedom of using NWP models; whereas, physical models must utilize NWP models [2]-[5]. Recently, it is prevalent that authors use a combination of a progressive statistical model and physical methods besides each other to reach an optimal approach that is applicable for longer horizons of forecasting system.

In these methods statistical model play supplemental role to data gathered by physical methods. In fact, models not utilizing numerical wind prediction suffer from lack of preciseness in time horizons more than 3 or 4 hours [6].

Although two main classes of techniques have been recognized for the wind prediction, (in [7] and [8], comprehensive reviews of these methods are prepared), as aforementioned, combination of statistical and physical methods are more prevalent than the others [9], [10]. Furthermore, several other spatial correlation techniques are proposed for short term wind power forecasting with the goal of achieving higher prediction accuracy [11]. However, by the passage of time, more advanced methods have been proposed. To this end, Artificial Neural Network (ANN) in [12], [13], ANN with adaptive Bayesian learning and Gaussian process approximation in [14], combination of ANN with wavelet transform in [15], fuzzy logic methods in [10], [16], Kalman filter in [17], support vector machine in [18] and some hybrid methods in [6] have been proposed for wind power prediction.

In this research paper, a new effective wind power forecasting method based on combination of measured data from SCADA and NWP model is proposed. The proposed method employs feed forward ANN with back propagation learning algorithm. In the course of the training process, the ANN utilized one year (on ten minutes interval basis) SCADA records of wind speed (as training input variable) and wind power (as training target variable).

Forecasted meteorological parameter (i.e. wind speed) from a NWP model is then applied as input to the developed (trained) ANN wind power prediction model in order to estimate the next day wind power output of an actual wind power system ('Goldwind microgrid wind turbine system', Beijing, China). The forecasting is for the next 24 hours with 10 minutes intervals. Simulation results show that the presented method can effectively enhance the exactness of the wind power forecasting.
The paper is organized as follows: Section 2 describes an overview of the wind power prediction. Section 3 introduces proposed model in which technique of employing SCADA system and NWP model is described. Descriptions of ANN as prediction system and the prediction results for the casestudies considered are provided in sections 4 and 5, respectively. The paper is concluded in section 6 .

\section{LITERATURE REVIEV OF SHORT- TERM WIND POWER FORECASTING APPROACHES}

The very short-term wind power prediction techniques utilize statistical models such as ARX, ARMA and Kalman Filters; while, they are mostly based on time series approach. In this category, the input data is past values of the forecasted variable like wind generation and wind speed; whereas, explanatory variables like temperature, wind direction and humidity can be employed in order to enhance precision and applicability of the forecasting methods. This model has the capability of prediction for horizons between 3-6 hours according to this consideration that they merely use the past production data [43].

In a hierarchical classification of short-term wind power prediction approaches, two major groups are consisting: 1) those that use manufacturer's power curve or empirical curves of wind turbines to map predicted wind speed to the generation output power, and 2) techniques in which wind generation power can be calculated directly without interfering the turbines' characteristics and role of NWP model is intensively highlighted for the short-term wind power forecasting [43]

The second approach is adopted in this research which combines measured data from SCADA records and NWP model without referring manufacturer's power curve or empirical curves of wind turbines.

Table 1. An overview of methods for short-term wind power prediction

\begin{tabular}{|l|}
\hline \multicolumn{1}{|c|}{ Short-Term Wind Power Prediction Models } \\
\hline Adaptive Neural Fuzzy System [30] \\
\hline Local Polynomial Regression [31] \\
\hline Bayesian Clustering by Dynamics (BCD) [32] \\
\hline Support Vector Machines [33] \\
\hline Mixture of Experts [33] \\
\hline Locally Recurrent Neural Networks [3] \\
\hline Autoregressive with Exogenous input (ARX) [34] \\
\hline $\begin{array}{l}\text { Autoregressive with Exogenous Input and } \\
\text { Multi-timescale Parameter (ARXM) [35] }\end{array}$ \\
\hline Random Forests [36] \\
\hline Neural Networks [37] \\
\hline
\end{tabular}




\section{WIND POWER PREDICTION MODEL}

\subsection{Proposed Wind Power Prediction Method}

In this research paper, a short term wind power forecasting using feed forward back propagation neural network (FFNN) is presented. The basic data sources for wind power prediction are historical measurement records of wind turbine SCADA system database and numerical weather prediction (NWP). To construct the model the forecasting system used historical measurement records of SCADA system database from a real wind power system ('Goldwind microgrid wind turbine system', Beijing, China).

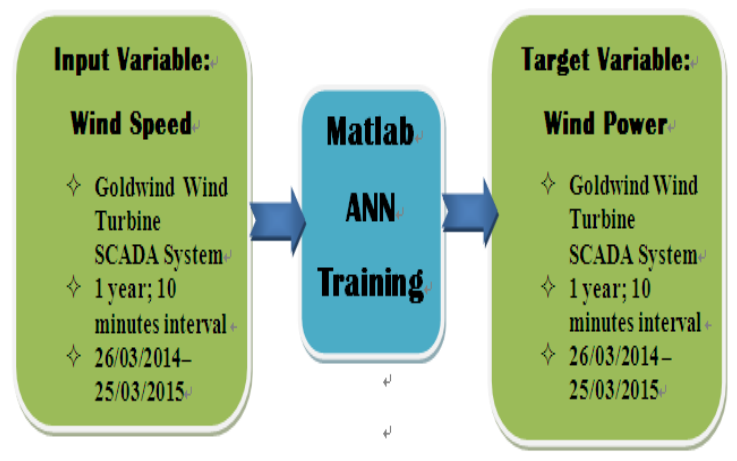

Figure 1. Block diagram illustration of ANN training

The ANN wind forecasting model has been trained utilizing 12 months data with 10 minutes interval provided from Goldwind wind turbine SCADA system. SCADA recorded wind speed and wind power data have been used as the network training input and target respectively as shown in Figure 1.

In the process of modeling, historical data provided from SCADA are used to train an ANN that effectively can estimate a transfer function between the specific patterns of input and output vectors.

Finally, the forecasted wind speed data provided from NWP model (WRF) projected around the vicinity of the wind farm has been preprocessed and applied to the developed (trained) ANN forecasting model in order to estimate wind power for the next 24 hours of the next day on 10 minutes interval basis as shown in Figure 2.

\subsection{Online SCADA System}

SCADA system as the nerve center and inseparable element of the wind farm plays a vital role for the prediction system. Usage of an online SCADA gives the operator freedom to oversee wind farm by supervising all of the wind turbines. This opportunity is provided for operator to set proper actions in critical situations by a 10 minutes record of the wind park turbines' information.

Moreover, this supervision system provides a comprehensive record of the wind speed and output powers as well as availability of turbines, which acts as a foundation for the short term wind power forecasting.

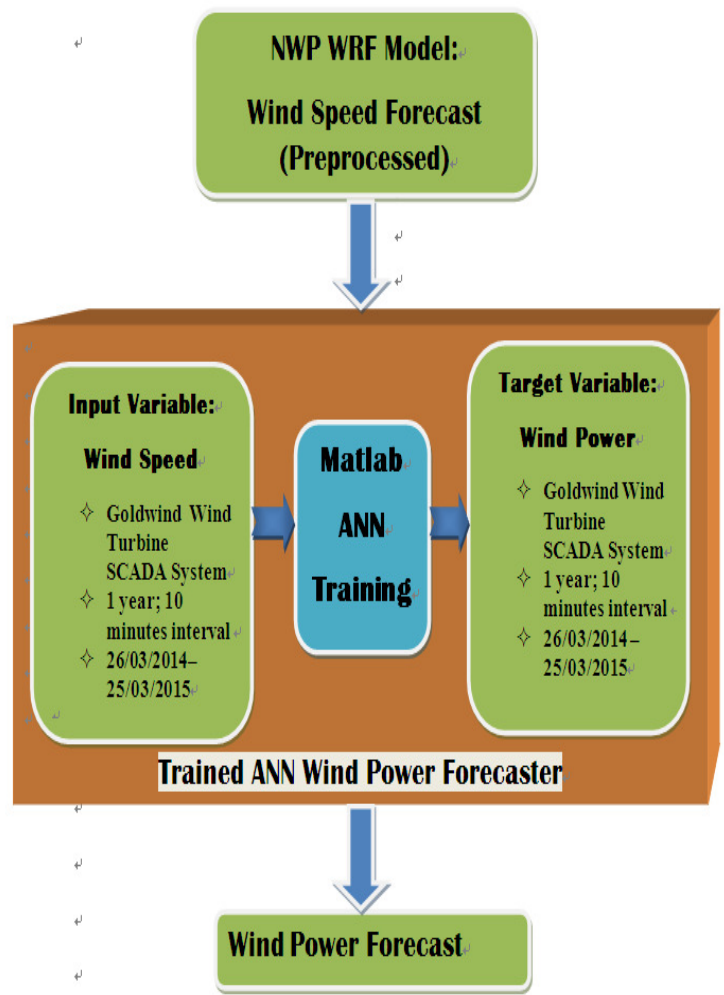

Figure 2. Block diagram illustration of ANN wind power forecaster for next day

\subsection{Numerical Weather Prediction (NWP) Model}

Nowadays, wind data has a non-negligible impact on wind power prediction. There are several approaches to obtain the wind data: observations, data mining and numerical weather simulations. The most straightforward and reliable way to obtain wind data is through on-site observations. However, they are not usually available.

Data mining is flexible, but its ability to downscale the weather data is limited. The NWP models use physical conservation of energy equations and this allows a more realistic downscaling of the data. In fact, high-resolution NWP of wind plays the key role for power forecasting.

In recent years, regarding availability of enhanced computational systems, many wind power estimation researches are directed utilizing NWP models wind data. This researchers use several NWP models like WRF, COSMO, MM5, and RAMS [30] - [33]. Also, various methods of extrapolation such as logarithmic law and wind shear power law have proposed by authors to provide appropriate wind information at the height of wind turbine hub (i.e. approximately $50 \mathrm{~m}$ ) using meteorological data that are gathered at $10 \mathrm{~m}$ above of the ground (According to World Meteorological Organization (WMO) approval)[19].

\section{PROPOSED FRAMEWORK OF ANN}

\subsection{Overview of ANN}

Neural network is a powerful data modeling tool that is able to capture and represent the complex input/output relationships. An Artificial Neural Network (ANN) is an information processing paradigm that is inspired by the way 
biological nervous systems, such as the brain, process information. The key element of this paradigm is the novel structure of the information processing system. It is composed of a large number of highly interconnected processing elements (neurons) working in unison to solve specific problems [45].

ANNs, like people, learn by example. An ANN is configured for a specific application, such as pattern recognition or data classification, through a learning process. Learning in biological systems involves adjustments to the synaptic connections that exist between the neurons. This is true of ANNs as well. And for the validation process ANN is followed, the human brain provides proof of the existence of massive neural networks that can succeed at those cognitive, perceptual, and control tasks in which humans are successful [45].

An illustrative representation of a multi-layer neural network is shown in Figure 3.

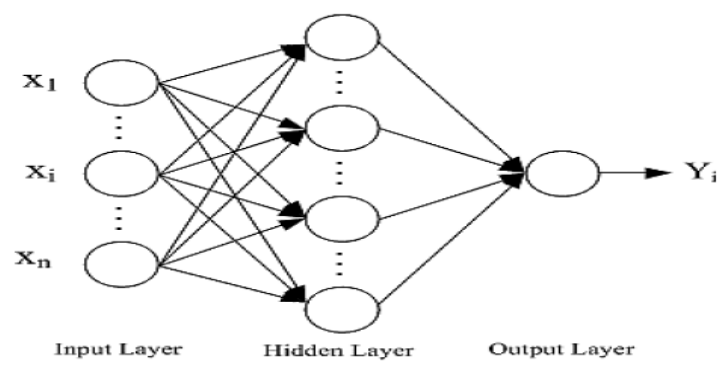

Figure 3. Multi-layer neural network

Where $\mathrm{X}_{\mathrm{i}}$ the $i^{\text {th }}$ input to the node (neuron) and $\mathrm{Y}_{\mathrm{i}}$ is the output of the node.

The mathematical equation which shows the relationship between the inputs $X_{i}$ to the network and the output $Y_{i}$ of the network is given by equations (1) below.

$$
Y_{i}=f_{i}\left(\sum_{j=1}^{n} W_{i j} \cdot X_{j}+b_{i}\right)
$$

Where $X_{j}$ is the $j^{\text {th }}$ input to the node, $Y_{i}$ is the output of the node, $W_{i j}$ is the connection weight between the input node and output node, $\mathrm{b}_{\mathrm{i}}$ is the bias of the node, and $f_{i}$ is known as activation function that determines the property of the neural network.

The mean squared error (MSE) of the network is defined by equations (2) below.

$$
M S E=\frac{1}{\mathrm{~N}} \sum_{i=1}^{N}\left(T_{i}-Y_{i}\right)^{2}
$$

Where $T_{i}$ is the target at $i^{\text {th }}$ pattern, $Y_{i}$ is the prediction of the network's output at $i^{\text {th }}$ pattern and $N$ is the number of training set samples.

\subsection{ANN Learning: Back Propagation Algorithm}

There are different types of training algorithms used for ANN learning; this paper used the Levenberg-Marquardz back propagation supervised training algorithm which is described in Figure 4 below.

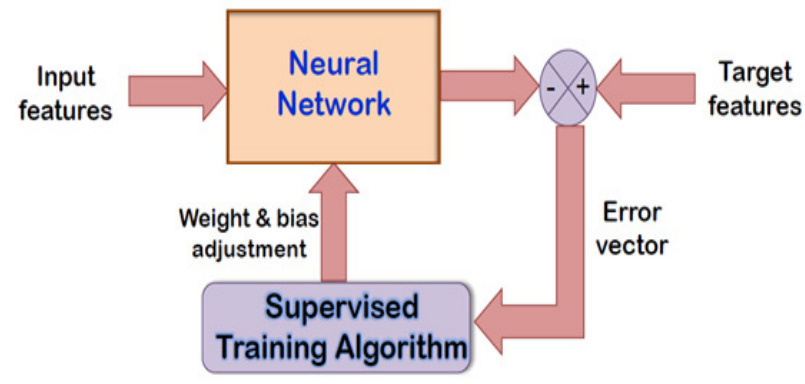

Figure 4. Back propagation supervised training algorithm

The back propagation algorithm cycles through two distinct passes, a forward pass followed by a backward pass through the layers of the network. The algorithm alternates between these passes several times as it scans the training data as described below [44]:

Forward Pass: Computation of outputs of all the neurons in the network

- The algorithm starts with the first hidden layer using as input values the independent variables of a case from the training data set.

- The neuron outputs are computed for all neurons in the first hidden layer by performing the relevant sum and activation function evaluations.

- These outputs are the inputs for neurons in the second hidden layer. Again the relevant sum and activation function calculations are performed to compute the outputs of second layer neurons.

Backward pass: Propagation of error and adjustment of weights

- This phase begins with the computation of error at each neuron in the output layer. A popular error function is the squared difference between $Y_{i}$ the output of node $i$ and $T_{i}$ the target value for that node.

- This error value is calculated continuously for each data point in the training data set, and the new value of the weight $\mathrm{W}_{\mathrm{ij}}$ of the connection from node $\mathrm{i}$ to node $\mathrm{j}$ is adjusted continuously until the error value reaches zero or falls below a certain threshold value.

- The backward propagation of weight adjustments along these lines continues until we reach the input layer.

- At this time we have a new set of weights on which we can make a new forward pass when presented with a training data observation.

\subsection{Wind Power Forecasting Accuracy Measures}

In order to evaluate the accuracy of the wind power prediction, the mean absolute error (MAE) and the mean absolute error percentage (MAPE) can be used. These criterions are defined as follows:

$$
M A E=\frac{1}{\mathrm{~N}} \sum_{h=1}^{N}\left|P_{h}^{a}-P_{h}^{f}\right|
$$




$$
M A P E=\frac{100 \%}{\mathrm{~N}} \sum_{h=1}^{N}\left|\frac{P_{h}^{a}-P_{h}^{f}}{P_{h}^{a}}\right|
$$

Where $\mathrm{P}_{\mathrm{h}}^{\mathrm{a}}$ and $\mathrm{P}_{\mathrm{h}}$ are the actual and forecasted wind power, respectively, at period $\mathrm{h}$, and $\mathrm{N}$ corresponds to the number of forecasted periods. The MAE is an average of the absolute errors. In MAPE the absolute values of all the percentage errors are added and the average is computed, producing a measure of relative overall fit.

Another criterion that may be used is the standard deviation (SD) that represents a measure of how spread out the numbers is.

$$
S D=\sqrt{\frac{1}{\mathrm{~N}-1} \sum_{h=1}^{N}\left(P^{f} h-\bar{P}\right)}
$$

Where $\bar{P}$ is the wind power average.

The root mean square error (RMSE) is another frequently used measure of the differences between forecasted and the actual observed values. The RMSE is the square root of the variance. RMSE gives a relatively high weight to large errors.

$$
R M S E=\sqrt{\frac{1}{\mathrm{~N}_{h=1}} \sum_{h=1}^{N}\left(P^{a} h-P^{f} h\right)^{2}}
$$

The RMSE is most useful when large errors are particularly undesirable. The MAE and the RMSE can be used together to diagnose the variation in the errors in a set of forecasts [46]. The RMSE will always be larger or equal to the MAE; the greater difference between them, the greater the variance in the individual errors in the sample [46]. In this case study the MAE, RMSE and SD have been used.

\section{CASE STUDY AND RESULTS}

In order to evaluate performance of the proposed wind power forecasting scheme, the prediction model was built for the Goldwind microgrid wind farm, Beijing, China. This wind farm has a single wind turbine with generating capacity of $2500 \mathrm{KW}$.

The wind speed and power time series of this wind farm are recorded from the $26^{\text {th }}$ March 2014 to the $25^{\text {th }}$ March 2015. The forecasting information is given for the next 4 days $\left(26^{\text {th }}\right.$ March 2015 to the $29^{\text {th }}$ March 2015) for every 10 minutes intervals.

The following figures present the system performance (testing of the wind power forecasting model) in the period of $26^{\text {th }}$ to $29^{\text {th }}$ March 2015.

Figures 5-8 show the comparison of the actual Goldwind wind turbine output power with those of the predicted output power for Goldwind microgrid wind turbine system for each of the four days ahead (26/03/2015 - 29/03/2015) of the last training date $(25 / 03 / 2015)$ on 10 minutes time-interval basis.
1 Day Ahead Wind Power Forecast for March 26, 2015

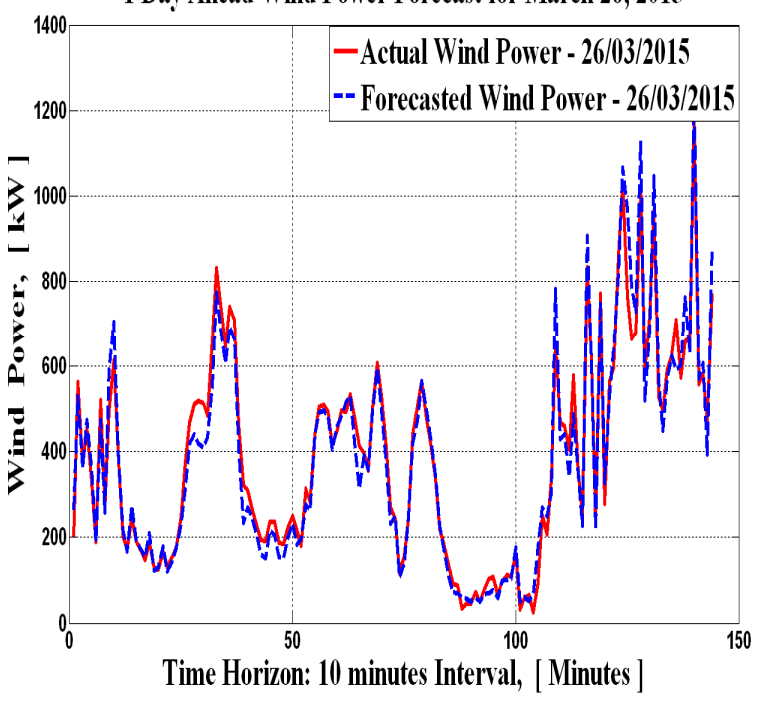

Figure 5. One Day-Ahead Wind Power Forecast for $26 / 3 / 2015$

Simulation results have shown that the predicted Goldwind microgrid wind turbine output power is almost similar with the actual wind power recorded by the SCADA which indicates the effective performance of the ANN wind power forecaster model that has been developed in the paper.

Table 2 presents the forecasting errors that have been calculated for each day's forecasting simulation. In order to evaluate the accuracy of the wind power prediction model developed in this paper, it was considered the mean absolute error (MAE), the root mean square error (RMSE), and the mean absolute percentage error (MAPE) as reported in section 4.

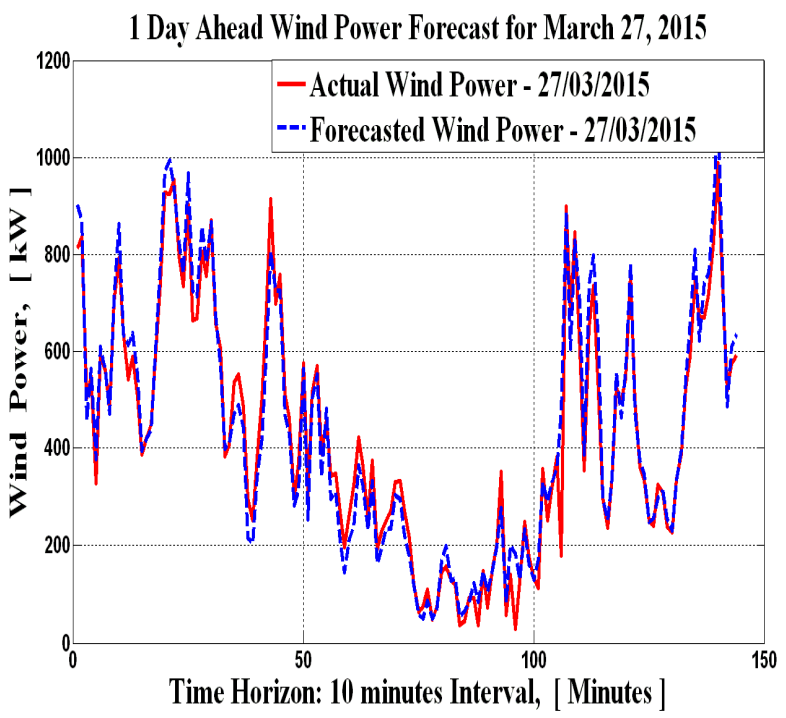

Figure 6. One Day-Ahead Wind Power Forecast for $27 / 3 / 2015$ 
1 Day Ahead Wind Power Forecast for March 28, 2015

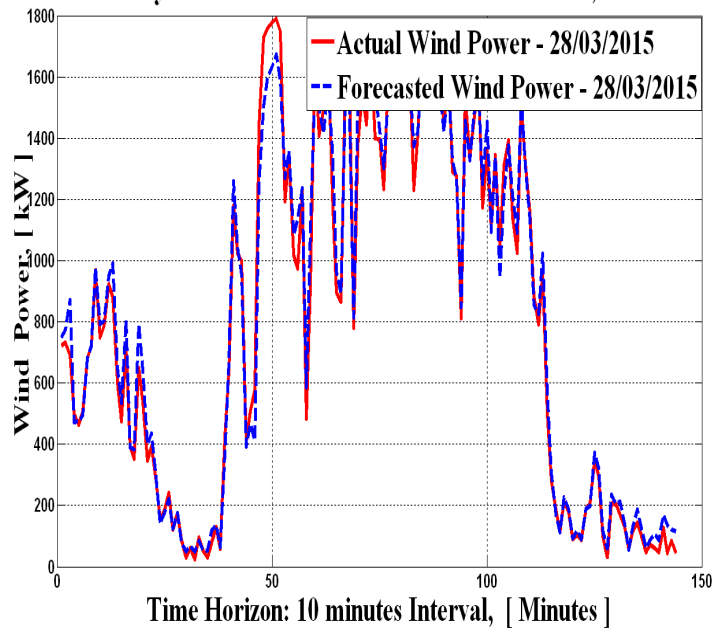

Figure 7. One Day-Ahead Wind Power Forecast for $28 / 3 / 2015$

Table 2. Wind power forecasting errors of each day

\begin{tabular}{|l|c|c|c|}
\hline \multirow{2}{*}{$\begin{array}{l}\text { Prediction } \\
\text { Day }\end{array}$} & \multicolumn{3}{|c|}{ Prediction Accuracy Measures } \\
\cline { 2 - 4 } & $\begin{array}{l}\text { MAE } \\
\text { (KW) }\end{array}$ & $\begin{array}{c}\text { RMSE } \\
\text { (KW) }\end{array}$ & $\begin{array}{c}\text { MAPE } \\
\text { (\%) }\end{array}$ \\
\hline $\begin{array}{l}\text { March 26, } \\
2015\end{array}$ & 35.8767 & 50.4804 & 12.1620 \\
\hline $\begin{array}{l}\text { March 27, } \\
2015\end{array}$ & 39.2858 & 53.4004 & 15.5106 \\
\hline $\begin{array}{l}\text { March 28, } \\
2015\end{array}$ & 52.2056 & 72.5210 & 12.0655 \\
\hline $\begin{array}{l}\text { March 29, } \\
2015\end{array}$ & 41.4318 & 65.7079 & 15.6206 \\
\hline
\end{tabular}

Prediction values of error obtained by method proposed in [6] is $17 \%$ for $24 \mathrm{~h}$ ahead (one day ahead or 144 ten minute intervals ahead) from a specific day. While, this error values for the presented paper are $12.1620 \%$ for March 26, 2015 , $15.5106 \%$ for March 27, 2015, 12.0655\% for March 28, 2015 and $15.6206 \%$ for March 29, 2015 that are severely lower than [6].

Moreover, the MAE and RMSE values presented in Table 2 have shown less error values than most of the literatures reported in this paper.

Results indicate that proposed method enjoys significantly effective performance for $24 \mathrm{~h}$ (144 ten minute intervals) ahead wind power forecasting.
1 Day Ahead Wind Power Forecast for March 29, 2015

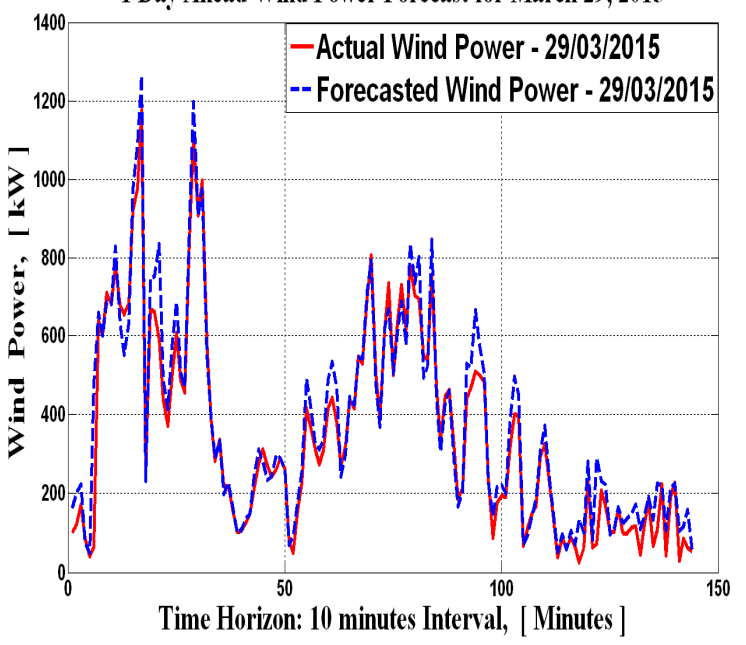

Figure 8. One Day-Ahead Wind Power Forecast for $29 / 3 / 2015$

\section{CONCLUSIONS}

In this research paper, a short term wind power prediction model, for day-ahead resource scheduling in microgrids, is proposed based on feed forward ANN for each 24 hours of the next day.

The proposed ANN prediction model is developed utilizing SCADA records of an actual wind farm ('Goldwind microgrid wind turbine system', Beijing, China) with a total installed power of $2500 \mathrm{KW}$ on Matlab neural network fitting tool using one year ten minutes interval data $(26 / 03 / 2014-25 / 03 / 2015)$ taken from Goldwind wind turbine SCADA system.

This model was tested to predict Goldwind wind turbine output power for four days ahead of the last training date $(26 / 03 / 2015$ - 29/03/2015) and the results of the prediction have been compared with the actual output power of Goldwind wind turbine system. Finally, the forecasted wind speed data provided from NWP model (WRF) projected around the vicinity of the wind farm has been preprocessed and applied to the developed (trained) ANN forecasting model in order to estimate wind power for the 24 hours of the next day on 10 minutes interval.

As demonstrated by the prediction results and the prediction error measures above, the predicted wind power has insignificant error and acceptable agreement with the actual wind power taken from Goldwind wind turbine SCADA system which shows the robustness and accuracy of the ANN wind power forecasting model developed in this paper. The model has resulted in desirable prediction accuracy and therefore, the forecasted wind power can be used as one of the input quantities for day-ahead resource scheduling in microgrids with high wind energy penetration. 


\section{REFERENCES}

[1] J. Juban, N. Siebert and G. N. Kariniotakis "Probabilistic short-term wind power forecasting for the optimal management of wind generation", in Proc. 2007 IEEE Lausanne Power tech, vol. 15, pp.683 - 688, 2007.

[2] M. C. Alexiadis, P. S. Dokopoulos, and H. S. Sahsamanoglou, "Wind speed and power forecasting based on spatial correlation models," IEEE Transactions on Energy Conversion, vol. 14, no. 3, pp. 836-842, Sep. 1999.

[3] T. G. Barbounis, J. B. Theocharis, M. C. Alexiadis, and P. S. Dokopoulos, "Long-term wind speed and power forecasting using local recurrent neural network models," IEEE Transactions on Energy Conversion, vol. 21, no. 1, pp. 273-284, 2006.

[4] L. Landberg, G. Giebel, H. A. Nielsen, T. Nielsen, and H. Madsen, "Short-term prediction-an overview," Wind Energy, vol. 6, no. 3, pp. 273-280, 2003.

[5] G. Giebel , L. Landberg , G. Kariniotakis and R. Brownsword "State-of-the-art on methods and software tools for short-term prediction of wind energy production", in Proc. EWEC, 2003.

[6] G. Sideratos and N. D. Hatziargyriou, "An advanced statistical method for wind power forecasting," IEEE Transactions on Power Systems, vol. 22, pp. 258-265, 2007.

[7] A. Costa, A. Crespo, J. Navarro, G. Lizcano, H. Madsen, and E. Feitosa, "A review on the young history of the wind power short-term prediction," Renewable \& Sustainable Energy Reviews, vol. 12, pp. 1725-1744, 2008.

[8] L. Ma, S. Y. Luan, C. W. Jiang, H. L. Liu, and Y. Zhang, "A review on the forecasting of wind speed and generated power," Renewable \& Sustainable Energy Reviews, vol. 13, pp. 915-920, 2009.

[9] L. Landberg, "Short-term prediction of the power production from wind farms", Journal of Wind Engineering and Industrial Aerodynamics, vol. 80, pp. 207-220, 1999.

[10] I. G. Damousis, M. C. Alexiadis, J. B. Theocharis, and P. S. Dokopoulos, "A fuzzy model for wind speed prediction and power generation in wind parks using spatial correlation," IEEE Transactions on Energy Conversion, vol. 19, no. 2, pp. 352-361, June 2004.

[11] T.G. Barbounis, J.B. Theocharis, "A locally recurrent fuzzy neural network with application to the wind speed prediction using spatial correlation," Neuro computing, vol. 70, pp. 1525-1542, 2007.

[12] Palomares-Salas, J.C., de 1 a Rosa, J.J.G.,Ramiro, J.G., Melgar, J., et.al, "ARIMA vs. Neural networks for wind speed forecasting", in Proc. IEEE International Conference on Computational Intelligence for Measurement Systems and Applications, pp. 129-133, 2009.

[13] L. Shuhui, D. C. Wunsch, E. A. O'Hair, M. G. Giesselmann, "Using neural networks to estimate wind turbine power generation," IEEE Transactions on Energy Conversion, vol. 16, no.3, pp. 276-282, Sept. 2001.
[14] R. Blonbou, "Very short-term wind power forecasting with neural networks and adaptive Bayesian learning", Renewable Energy, pp. 1118-1124, 2011.

[15] J.P.S. Catalao, H.M.I. Pousinho, V.M.F. Mendes, "Shortterm wind power forecasting in Portugal by neural networks and wavelet transform", Renewable Energy, pp. 1245-1251, 2011

[16] G. Sideratos and N. Hatziargyriou, "Using radial basis neural networks to estimate wind power production," in Proc. IEEE Power and Energy Soc. General Meeting, pp. $1-7,2007$.

[17] P. Louka, G. Galanis, N. Siebert, G. Kariniotakis, P. Katsafados, I. Pytharoulis and G. Kallos, "Improvements in wind speed forecasts for wind power prediction purposes using Kalman filtering," Journal of Wind Engineering and Industrial Aerodynamics, vol.96, pp. 2348-2362, 2008.

[18] D. Ying, J. Lu, Q. Li, "Short-term wind speed forecasting of wind farm based on least square-support vector machine," Power Systems Technology, vol.32, no. 15, pp. 62-66, 2008.

[19] Y. Charabi "Arabian summer monsoon variability: teleconexion to ENSO and IOD", Atmospheric Research, pp. 105-117, 2009.

[20] P. Pinson, L.E.A. Christensen, H. Madsen, P. Sørensen, M.H. Donovan, and L.E. Jensen,"Regime-switching modelling of the fluctuations of offshore wind generation," Journal of Wind Engineering \& Industrial Aerodynamics, vol. 96, no. 12, pp. 2327-2347, 2008.

[21] G. Kariniotakis, E. Nogaret, and G. Stavrakakis, "Advanced Short-Term Forecasting of Wind Power Production," in Proc. European Wind Energy Conference EWEC'97, Ireland, pp. 751-754, October 1997.

[22] I.G. Damousis and P. Dokopoulos, "A fuzzy model expert system for the forecasting of wind speed and power generation in wind farms," in Proc. IEEE International Conference on Power Industry Computer Applications PICA 01, pp. 63-69, 2001.

[23] I.J. Ramírez-Rosado and L.A. Fernández-Jiménez, "Next-day wind farm electric energy generation forecasting using fuzzy time-series," in Proc. International Conference on Modeling, Identification, and Control, Innsbruck, Austria, pp. 237-240, 2003.

[24] G. Kariniotakis, E. Nogaret, A.G. Dutton, J.A. Halliday, and A. Androutsos, "Evaluation of Advanced Wind Power and Load Forecasting Methods for the Optimal Management of Isolated Power Systems," in Proc. European Wind Energy Conference EWEC'99, pp. 1082-1085, Nice, France, March 1-5, 1999.

[25] E.A. Bossanyi, "Short-Term Wind Prediction Using Kalman Filters," Wind Engineering, vol. 9, no. 1, pp. 18, 1985.

[26] S. Alpay, L. Bilir, S. Ozdemirny, and B. Ozerdem, "Wind speed time series characterization by Hilbert transform," International Journal of Energy Research, vol. 30, pp. 359-364, 2006.

[27] R.E. Abdel-Aal, M.A. Elhadidy, and S.M. Shaahid, "Modeling and forecasting the mean hourly wind speed 
time series using GMDH-based abductive networks," Renewable Energy, vol. 34, no. 7, pp. 1686-1699, July 2009.

[28] C.W. Potter and M. Negnevistky, "Very short-term wind forecasting for Tasmanian power generation," IEEE Transactions on Power Systems, vol. 21, no. 2, pp. 965972, 2006.

[29] T.H.M. El-Fouly, E.F. El-Saadany, and M.M.A. Salama, "Grey Predictor for Wind Energy Conversion Systems Output Power Prediction," IEEE Transactions on Power Systems, vol. 21, no. 3, pp. 1450-1452, 2006.

[30] M. Negnevitsky, P. Johnson, and S. Santoso, "Short term Wind Power Forecasting using hybrid intelligent systems," in Proc. IEEE Power Engineering Society General Meeting, pp. 1-4, June 24-28, 2007.

[31] Ismael Sanchez, "Short-term prediction of wind energy production," International Journal of Forecasting, vol. 22, no. 1, pp. 43-56, 2006.

[32] Shu Fan, James R. Liao, Ryuichi Yokoyama, and Luonan Chen, "Forecasting the Wind Generation Using A Twostage Hybrid Network Based on Meteorological Information," Information and Communications Engineering, Osaka Sangyo University, 2006.

[33] R. Jursa, "Wind power prediction with different artificial intelligence models," in Proc. European Wind Energy Conference EWEC'07, Milan, Italy, May 2007.

[34] Mario J. Duran, Daniel Cros, and Jesus Riquelme, "Short-Term Wind Power Forecast Based on ARX Models," Journal of Energy Engineering, vol. 133, no. 3, pp. 172-180, Sept. 2007.

[35] A. Yamaguchi, T. Ishihara, K. Sakai, T. Ogawa, and Y. Fujino, "A Physical-Statistical Approach for the Regional Wind Power Forecasting," in Proc. European Wind Energy Conference EWEC'07, Milan, Italy, 2007.

[36] Lionel Fugon, Jérémie Juban, and G. Kariniotakis, "Data mining for Wind Power Forecasting," in Proc. European Wind Energy Conference EWEC'08, Brussels, Belgium, April 2008.

[37] A. Kusiak, H.-Y. Zheng, and Z. Song, "Wind Farm Power Prediction: A Data-Mining Approach," Wind Energy, vol. 12, no. 3, pp. 275-293, 2009.

[38] Kariniotakis, G.N., Pinson, P., "Uncertainty of short-term wind power forecasts a methodology for on-line assessment", in Proc. 2004 International Conference on Probabilistic Methods Applied to Power Systems, pp. 729-736, 2004.

[39] J. Connors, D. Martin, and L. Atlas, "Recurrent neural networks and robust time series prediction", IEEE Transactions on Neural Networks, vol. 5, pp. 240 - 254, 1994.

[40] E. Atashpaz-Gargari and C. Lucas, "Imperialist Competitive Algorithm: An Algorithm for Optimization Inspired by Imperialistic Competition", in Proc. IEEE Congress on Evolutionary Computation (CEC 2007), pp. 4661-4667, 2007.

[41] Sh. Mollaiy Berneti, M. Shahbazian, "An Imperialist Competitive Algorithm Artificial Neural Network Method to Predict Oil Flow Rate of the Wells", International Journal of Computer Applications, 2011.
[42] National Climate Data and Information Archive, [Online]. Available: http://www.climate.weatheroffice.gc.ca

[43] Ghadi, M. Jabbari, S. Hakimi Gilani, H. Afrakhte, and A. Baghramian, "A novel heuristic method for wind farm power prediction: A case study", International Journal of Electrical Power \& Energy Systems, 2014.

[44] ocw.mit.edu

[45] ijecs.in

[46] www.eumetcal.org.uk

[47] stonito.com

[48] M. Jabbari, Ghadi, S. Hakimi Gilani, H. Afrakhte and A. Baghramian, "Short-Term and Very Short-Term Wind Power Forecasting Using a Hybrid ICA-NN Method," International Journal of Computing and Digital Systems, vol. 3, No. 1, 63-70 (2014). 